\title{
Micromechanical Model of Dry Friction Hybrid Polymer Composite Clutch Facings
}

\author{
R. BICZÓ1, G. KALÁCSKA² \\ 1Szent István University, Faculty of Mechanical Engineering, rolbicz@gmail.com \\ ${ }^{2}$ Szent István University, Faculty of Mechanical Engineering, kalacska.gabor@gek.szie.hu
}

Abstract. Modelling the complex coupled thermomechanical and tribological contact of a dry friction clutch system between cast iron flywheel and scatter-wound hybrid composite clutch facing requires a thought through investigation of the friction material properties and behaviour. Challenges of the creation of a mechanical stiffness matrix for such a complex material are described in this paper along with simplification ideas and solutions.

\section{Introduction}

Requirements of composite friction materials derive from the operating characteristics of their applications. A clutch shown in figure 1. transfers the kinetic energy of a rotating crankshaft - coupled to a power source - to the transmission and wheels. Slippage results in the generation of heat, which is absorbed and eventually dissipated to the atmosphere by the clutch. [2] To fulfil these requirements typical components of polymer composite friction materials for clutches can be classified in the following groups: reinforcements, binders, friction modifiers, and fillers. Since there are more than two components such composites are called hybrid composites. The manufacturing steps for the investigated fibre reinforced woven clutch facings are wire preforming, dry mixing of fillers and modifiers, molding of mix around strand or wire preforms (coating), weaving according to a specified pattern, then hot pressing, curing and grinding. To determine the material properties of such materials isn't always possible through standard methods especially when some components are industrial secrets. The aim of this paper is to describe the challenges of the creation of a mechanical stiffness matrix for such a complex material along with suggestions for simplification ideas and solutions.
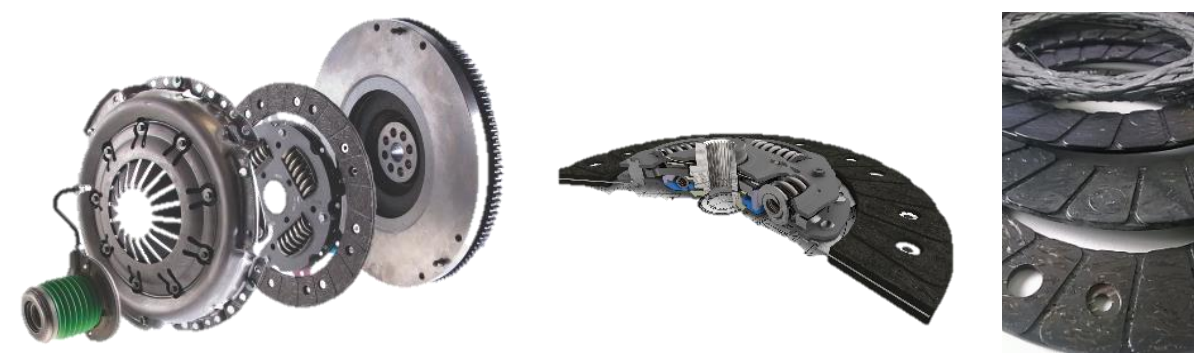

Figure 1. From left to right: Parts of a dry clutch system, dry clutch plate, products of phases of dry friction material production [1] 


\section{Material model creation method}

\subsection{The idea of separation and ROM}

In our case the hybrid composite can be derived into two main component groups. The first group is long fibre reinforcement that consists of glass fibre, copper, aromatic polyamide and poly-acryl-nitrile. The second group is the so called matrix, that is also a hybrid composite itself with short fibre reinforcement, fillers, sulfur, phenol and melamine resin etc. in it. The two groups then united by coating. Taking the secret properties and the special orientation due to wreath-waving production method into consideration the idea is to determine the mechanical properties of these two component groups separately and then utilize a rule of mixture (ROM) to create a mechanical stiffness matrix.

\subsection{Uniting the results with ROM}

Such rule of mixtures (ROMs) are utilized in micromechanical models like Chamis's [3] semi empiric model for unidirectional composites, Halpin-Tsai [4] equations also for unidirectional composite materials or Tsai-Pagano [5] model for randomly oriented fibrous composites. All of these deal separately with fiber and matrix properties then unites them to evaluate mechanical properties of the whole composite. The Tsai-Pagano equations are:

$$
\begin{aligned}
E_{11}^{*} & =E_{m} * V_{m}+E_{f} * V_{f}, \\
E_{22}^{*} & =\frac{E_{f} * E_{m}}{E_{f}-\sqrt{V_{f}}\left(E_{f}-E_{m}\right)}, \\
E & =\frac{3}{8} E_{11}^{*}+\frac{5}{8} E_{22}^{*}, \\
G & =\frac{1}{8} E_{11}^{*}+\frac{1}{4} E_{22}^{*}, \\
v & =\frac{E}{2 G}-1,
\end{aligned}
$$

where:

- $\mathrm{E}_{\mathrm{m}} ; \mathrm{V}_{\mathrm{m}}$ - elastic modulus and volume of the matrix component group,

- $\mathrm{E}_{\mathrm{f}} ; \mathrm{V}_{\mathrm{f}}$ - elastic modulus and volume of the long fibre reinforcement component group,

- $\mathrm{E}_{11} *$ - fictive elastic modulus in the direction of load,

- $\mathrm{E}_{22}{ }^{*}$ - fictive elastic modulus perpendicular to the direction of load,

- E - effective elastic modulus,

- G-effective shear modulus,

- $v$ - effective Poisson's ratio. 


\section{Necessary measurements}

\subsection{Properties of the matrix component group}

To evaluate the properties of the 'matrix component group' facings made only of coating matrix were produced without fibre reinforcement. Via abrasive water jet cutting test specimen were created from these facings. Tensile test according to DIN 53455, two directional strain measurement and Iosipescu shear test were carried out to determine the tensile strength, elastic modulus, Poisson's ratio and shear modulus of the matrix.

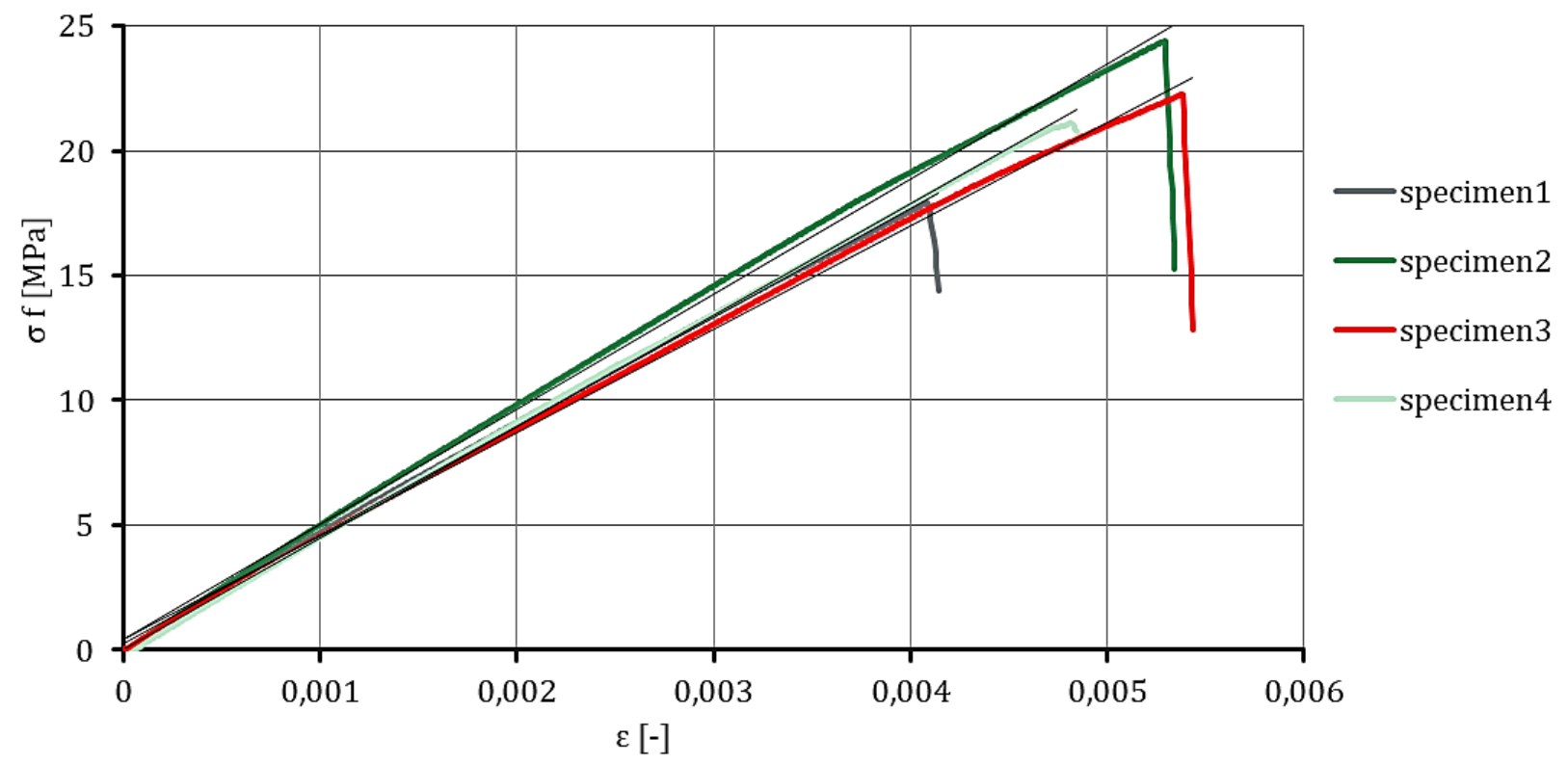

Figure 2.Tensile test results: stress-strain curve of the matrix component group
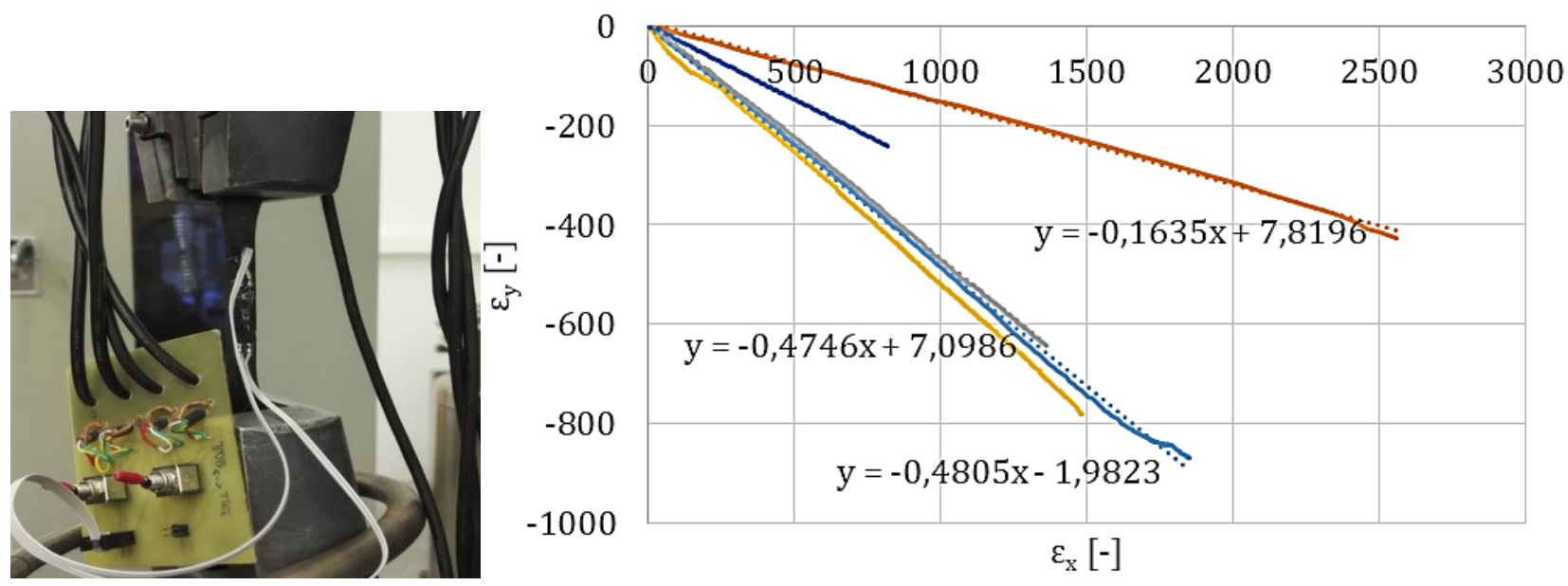

Figure 3. Poisson coefficient measurement with two directional strain-detection 


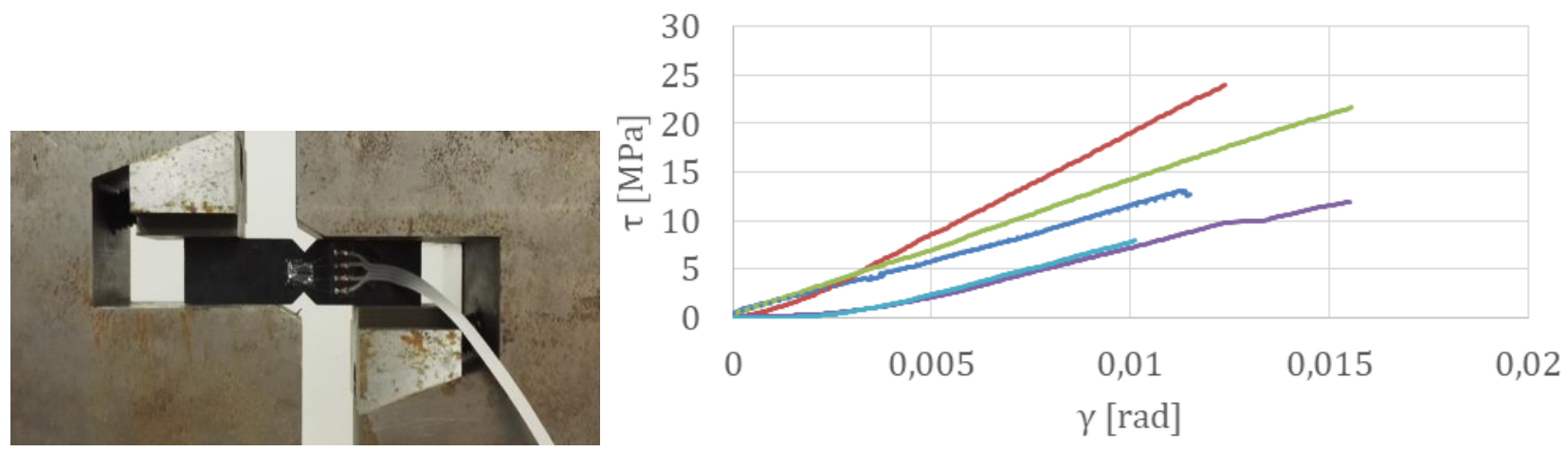

Figure 4. Iosipescu shear test setup and results of specimens

The mean values of the measured properties are the following:

\begin{tabular}{|l|c|}
\hline Young Modulus [MPa] & 4290 \\
\hline Poisson Coefficient & 0,38 \\
\hline Shear Modulus [MPa] & 1290 \\
\hline
\end{tabular}

Table 1. Properties of the matrix component group

\subsection{Properties of the long fibre reinforcement component group}

For evaluating the mechanical properties of long fibre reinforcement standard tests of Schaeffler Savaria Ltd. were utilized and the lowest fibre Poisson ratio was taken into account.

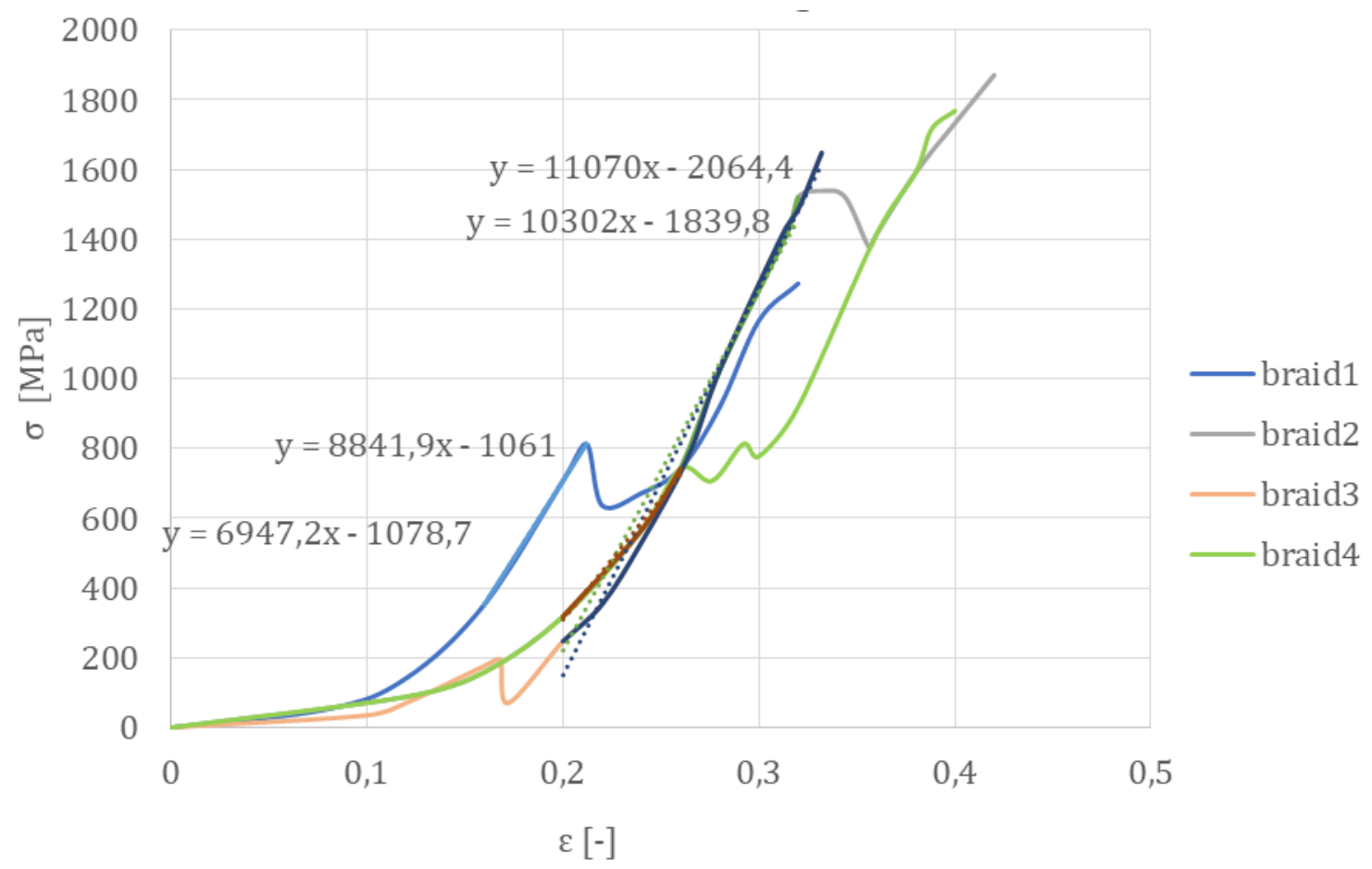

Figure 5. Stress-strain curves of woven braids, the long-fibre-reinforcement group 
From the measurements the Young Modulus of the long-fibre-reinforcement component group can be evaluated with $27300 \mathrm{MPa}$ mean value. This group's Poisson coefficient will be represented with one of it's components value, the glass fibre poisson number: 0,2. [6] The Shear Modulus can be evaluated through calculation and results in $11380 \mathrm{MPa}$.

\section{Creating the material model}

If the reinforcement was parallel to the loads the elements of the stiffness matrix would be:

$$
\begin{aligned}
& E_{11}=E_{m} * V_{m}+E_{f} * V_{f}=14,3 \mathrm{GPa} \\
& E_{22}=\frac{E_{f} * E_{m}}{E_{m} * V_{f}+E_{f} * V_{m}}=6,78 \mathrm{GPa} \\
& v_{12}=v_{m} * V_{m}+v_{f} * V_{f}=0,3 \\
& v_{21}=\frac{E_{22}}{E_{11} * v_{12}=0,144} \\
& G_{12}=\frac{G_{f} * G_{m}}{G_{m} * V_{f}+G_{f} * V_{m}}=2,1 \mathrm{GPa} \\
& \boldsymbol{S}=\left[\begin{array}{ccc}
\frac{1}{E_{11}} & -\frac{v_{12}}{E_{11}} & 0 \\
-\frac{v_{21}}{E_{22}} & \frac{1}{E_{22}} & 0 \\
0 & 0 & \frac{1}{G_{12}}
\end{array}\right]=\left[\begin{array}{ccc}
\frac{1}{14,3} & -\frac{0,3}{14,3} & 0 \\
-\frac{11}{6,78} & \frac{1}{6,78} & 0 \\
0 & 0 & \frac{1}{2,1}
\end{array}\right] \mathrm{GPa}
\end{aligned}
$$

Creating a cylindrical coordinate system and knowing that the fibres are positioned in $47^{\circ}$ to the direction of the radial coordinate direction one can set up a transformation matrix:

$$
\boldsymbol{T}=\left[\begin{array}{ccc}
\cos ^{2} \lambda & \sin ^{2} \lambda & 2 \sin \lambda \cos \lambda \\
\sin ^{2} \lambda & \cos ^{2} \lambda & -2 \sin \lambda \cos \lambda \\
-\sin \lambda \cos \lambda & \sin \lambda \cos \lambda & \cos ^{2} \lambda-\sin ^{2} \lambda
\end{array}\right]
$$

Utilising the rule of mixtures as if we were dealing with a laminate and taking into consideration the sinusoidal running of the coated fibre in the wraith, that the facing is created from through vulcanization steps, the missing mechanical material properties in a cylindrical coordinate system $[\mathrm{r}, \varphi, \mathrm{z}]$ for the facing are:

\begin{tabular}{|l|c|}
\hline $\mathrm{E}_{\mathrm{rr}}[\mathrm{GPa}]$ & 6,06 \\
\hline $\mathrm{E}_{\varphi \varphi}[\mathrm{GPa}]$ & 6,26 \\
\hline$v_{\mathrm{r} \varphi}$ & 0,454 \\
\hline$v_{\varphi \mathrm{r}}$ & 0,469 \\
\hline $\mathrm{G}_{\mathrm{r} \varphi}[\mathrm{GPa}]$ & 3,83 \\
\hline
\end{tabular}

Table 2. Properties of the fibre reinforcement in the cylindrical coordinate system 
Properties of the kvasi-laminate are as follows:

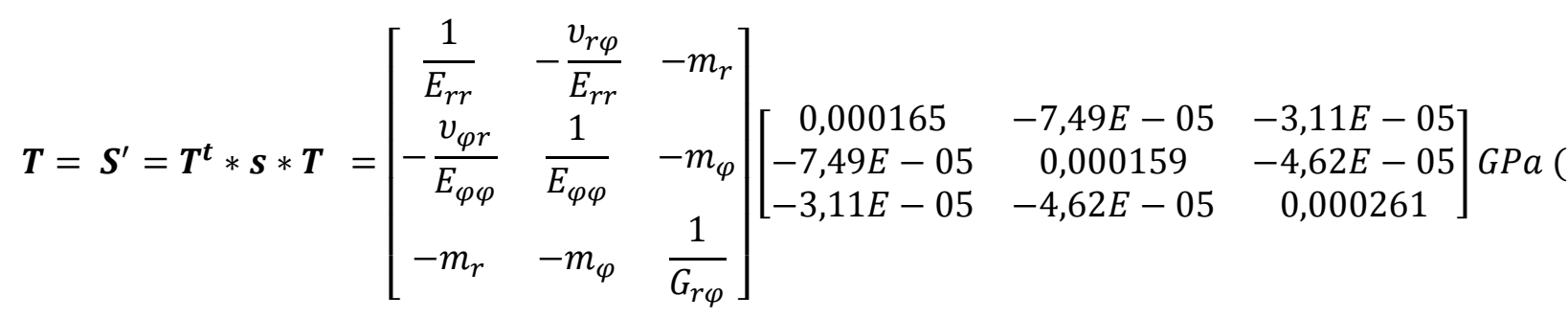

Thorugh the extensional stiffness matrix creation for laminates [6] the material properties of the facing are:

$$
\begin{aligned}
& E_{r r}=\frac{Q_{11} Q_{22}-Q_{12}^{2}}{Q_{22}}=12,3 \mathrm{GPa}, \\
& E_{22}=\frac{Q_{11} Q_{22}-Q_{12}^{2}}{Q_{11}}=12,3 \mathrm{GPa}, \\
& v_{12}=\frac{Q_{12}}{Q_{22}}=0,46, \\
& G_{12}=Q_{66}=7,6 \mathrm{GPa} .
\end{aligned}
$$

\section{Conclusions}

Modelling the complex hybrid mechanical material system of scatter-wound hybrid composite dry friction clutch facing has been carried out with the idea of separated component group creation and ROM. The stiffness matrix and it's components can be utilised in further finite element investigations like thermo-mechanically coupled tribological analyses.

\section{References}

[1] LuK symposia $1986-2006$

[2] M. G. Jacko - S. K. Rhee, Brake Linings and Clutch Facings. Kirk-Othmer Encyclopedia of Chemical Technology, 144-154.

[3] C. C. Chamis, Mechanics of composite materials: past, present, and future. Nasa Technical Memorandum; 3-14.

[4] J. C. Halpin - J. L. Kardos, The Halpin-Tsai equations: A review. Polymer Engineering and Science, , Vol. 16, No. 5.

[5] S. W. Tsai - N. J. Pagano, Invariant properties of composite materials. In: Tsai S. W., Halpin J. C., Pagano N. J., editors. Composite materials workshop, Technomic Publishing Company; 233-53.

[6] P. K. Mallick, Fiber reinforced composites - materials, manufacturing and design, CRC Press, 52. 